\title{
MONITORING CHLOROPHYLL-A AND SEA SURFACE TEMPERATURE WITH SATELLITE DATA DERIVED FROM MULTIPLE SENSORS
}

\author{
A. Tuzcu Kokal ${ }^{1 *}$, N. Musaoğlu ${ }^{1}$ \\ ${ }^{1}$ Istanbul Technical University, Civil Engineering Faculty, Department of Geomatics Engineering, 34469 Maslak, Istanbul \\ TURKEY - (tuzcuay, musaoglune)@itu.edu.tr
}

Commission III, WG III/9

KEY WORDS: Remote Sensing, Water Quality, Chlorophyll-a, Sea Surface Temperature, CDS Climate, HLS.

\begin{abstract}
:
Water is an essential natural source for human being and environment. To conserve water sources, monitoring them by using remote sensing data and technologies is an efficient way. In this study, water quality of the Sea of Marmara (Turkey), which has lots of currents, was examined. The main aim of the study was developing a common model to monitor chlorophyll-a concentration in time by using satellite data. After, the coefficients of the OC2 (ocean chlorophyll 2) model were detected by curve fitting, it was applied to Landsat images. The bias and RMSE (Root Mean Square Error) were found as $0.73 \mu \mathrm{g} / 1$ and $5.80 \mu \mathrm{g} / 1$, respectively. The high RMSE was stemmed from dynamic structure of the sea. Thus, the temporal resolution has a profound impact on the accuracy of estimations. The developed model was applied to the HLS (Harmonized Landsat Sentinel-2) data, which has high temporal resolution. The results of the HLS and Landsat images were compared, and HLS is found as proper to monitor the water quality. The combined data (SST (Sea Surface Temperature) daily data from 1981 to present derived from satellite observations Level-4 product) was used for the secondary aim of the study which was monitoring SST. The bias and RMSE of the data, which was acquired on 19.07.2017, were found as $0.33^{\circ} \mathrm{C}$ and $1.12^{\circ} \mathrm{C}$, respectively. The bias and RMSE of the data, which was acquired on 18.07 .2018 , were found as $-0.02^{\circ} \mathrm{C}$ and $1.03{ }^{\circ} \mathrm{C}$, respectively. The combined data is found appropriate to monitor the SST.
\end{abstract}

\section{INTRODUCTION}

Remote sensing data and technologies are efficient tools to monitor extreme hydroclimatic events, water quality and water quantity (Chawla et al., 2020). Chlorophyll-a, colored dissolved organic matter, total suspended solids (TSS), Secchi disc depth and turbidity, which are some of the water quality parameters, were detected by using remote sensing data and technologies in a large number of research (Gholizadeh et al., 2016; Chawla et al., 2020; Tuzcu, et al., 2019). Monitoring the chlorophyll-a concentration is possible by using the reflected and absorbed sunlight information and this provides valuable information about the ocean environment (Url-1). SST, which can be detected by using the thermal infrared region of the optical satellite sensors, is an important indicator of the water quality and global warming (Fingas, 2019).

There are several case studies about assessing water quality by using remote sensing data and technologies in the world. In one of them, Kim et al., (2017) researched on detecting amount of chlorophyll-a and TSS in Korean West coast by using MODIS data. It was concluded that, temperature had an important impact on chlorophyll-a concentration and also, tides effected the total suspended solid. Arias-Rodriguez et al., (2020) researched on detecting two of water quality parameters, which were turbidity and Secchi disk depth, of Valle de Bravo reservoir (Mexico) by using the field data and MERIS data. For that purpose, machine learning algorithms were applied. In addition, changes in the water quality in years between 2002 and 2012 were assessed. It was concluded that, drought have a profound impact on decreasing water quality. In another case study, changes in water quality and quantity of Harike wetland (India) in time was examined by using multispectral Resourcesat 2 LISS-IV satellite data. It was seen that increment of cultivation and decrement of groundwater level had an adverse impact on the wetland (Singh et al., 2020). Constantin et al, (2016) researched on detecting turbidity of Danube River plume by using MODIS data and the field data. As a result, it was seen that there is a high correlation between river discharge and the turbidity of the coastal sides. In another case study, Belgian Coastal Zone was examined by Sentinel 3 satellite data in terms of chlorophyll-a and suspended particulate matter. For this purpose, various processors, which are ACOLITE, L2-WFR, SeaDAS, SeaDAS-ALT, POLYMER, C2RCC, had compared with each other. Best results were achieved by using ACOLITE and L2-WFR processors (Vanhellemont and Ruddick, 2021). Sunar, (1992) researched on detecting the water quality situation in the İzmit Bay (Turkey) by using Landsat 5 TM. For that purpose, classification algorithms were used and variations in patterns in the image were detected to make predictions. Ormeci et al., (2009) analysed the chlorophyll-a concentration in the Golden Horn, which is one of the most researched part in the Sea of Marmara, by using IKONOS satellite data and the in-situ data. For that purpose, regression analysis was performed. It was seen that locations and amount of the in-situ measurement have an important effect on analysis. In one of the other case studies, impact of the land use / cover changes on the water quality of Küçükçekmece Lake, which is directly connected with the Sea of Marmara, was researched. Water quality maps were produced by using a multiple regression analysis technique and Landsat 5 satellite data. As a conclusion, it was detected that there was an increment of approximately 260 ha in residential areas from 1992 to 2000 and the increment had an adverse impact on the water quality

\footnotetext{
* Corresponding author
} 
(Alparslan et al., 2009). Ikis, (2007) analyzed changes in concentrations of chlorophyll-a from 1997 to 2007 in the Sea of Marmara by using SeaWiFS and MODIS-Aqua data. It was seen that, the amount of phytoplankton blooms reached at maximum level in spring and winter periods. Moreover, high level of phytoplankton blooms was seen at east side of the sea. The reason of this situation may be stemmed from the discharge that coming from the industrial area. Ekercin, (2007) researched on assessing chlorophyll-a, TSS and SDD concentrations in the Golden Horn by using the in-situ and IKONOS data. For that purpose, multiple regression method was used. As a result, high determination coefficients were obtained, and it was seen that although IKONOS data has low spectral resolution, it is a proper tool to monitor water quality because of having high spatial resolution.

In this study, assessment of the water quality of the Sea of Marmara in terms of chlorophyll-a and SST was aimed. For that purpose, satellite data, which are Landsat 8, HLS and the combined data, were used. Among these data, Landsat 8 and HLS were used to detect chlorophyll-a concentration in the Sea of Marmara. In order to detect chlorophyll-a concentration, OC2 (O'Reilly et al., 1998) model was applied to the satellite images. Curve fitting was applied to estimate the coefficients of the OC2 model and after the coefficients were obtained, the model was applied to the Landsat 8 and HLS data. In addition, the combined data was used to detect the SST. To assess the accuracy of the data, the combined data and in situ data were compared.

\section{DATA AND METHODOLOGY}

\subsection{Study Area}

The Sea of Marmara (Turkey), which is an inland sea and connected to Black Sea and the Aegean Sea via the Bosphorus strait and the Dardanelles strait, respectively, has a profound impact on climate conditions and incubation for the marine life (TÜDAV, 2017). The Sea of Marmara has a salinity level higher than the Black Sea, but lower than the Aegean Sea. Density difference caused by different salinity levels generates currents between Black Sea and Aegean Sea via the Sea of Marmara and Turkish straits. Surface currents caused by the lower density of the Black Sea carries water with lower salinity to the Sea of Marmara (Beşiktepe et al., 1994, Url-5). This current also carries pollution, which is caused by pollutants such as the Danube River. With a lesser degree, river estuaries such as Susurluk River, which is a river at the southern side of the Sea of Marmara, discharge pollution to the Sea of Marmara (PAP/RAC, 2005; SPO, 2001; Url-5). The study area and station points of the insitu data that acquired from (MAREM (Marmara Environmental Monitoring) Project (Artüz et al., 2018) in July, 2017 were shown in Figure 1.

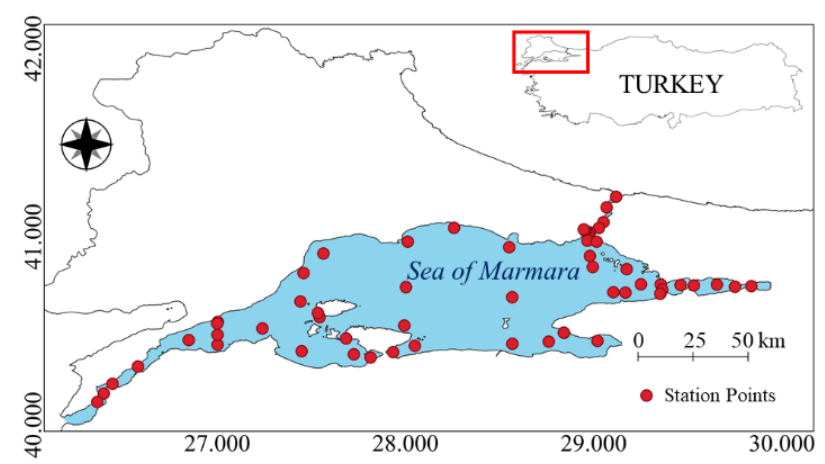

Figure 1. The study area.

\subsection{Data Used}

In this scope, chlorophyll-a concentration and SST, which are important water quality parameters, were examined. For that purpose, satellite data and field data were used to determine water quality.

2.2.1 Field Data: The field data was acquired from MAREM Project (Artüz et al., 2018; Artüz et al., 2020), which is a free and open data, and used as a reference data. The station points were located as to characterize the water quality of the sea. The number of the samples are 57 and 51 in summer seasons, respectively in 2017 and 2018. Table 1 shows the dates of field campaigns of MAREM Project (Artüz et al., 2018; Artüz et al., 2020) and the number of samples. Figure 2 represents the graph of the station points and their chlorophyll-a values.

\begin{tabular}{|l|l|c|}
\hline $\begin{array}{l}\text { Field } \\
\text { Campaign }\end{array}$ & Parameter & Number of Samples \\
\hline $\begin{array}{l}\text { 2017 Summer } \\
(15 / 07 / 2017\end{array}-$ & Chlorophyll-a & 57 \\
\cline { 2 - 3 } $23 / 07 / 2017)$ & SST & 57 \\
\hline $\begin{array}{l}2018 \text { Summer } \\
(15 / 07 / 2018 \\
21 / 07 / 2018)\end{array}$ & Chlorophyll-a & 51 \\
\cline { 2 - 3 } & SST & 51 \\
\hline
\end{tabular}

Table 1. Dates of field campaigns of MAREM (Artüz et al., 2018; Artüz et al., 2020)
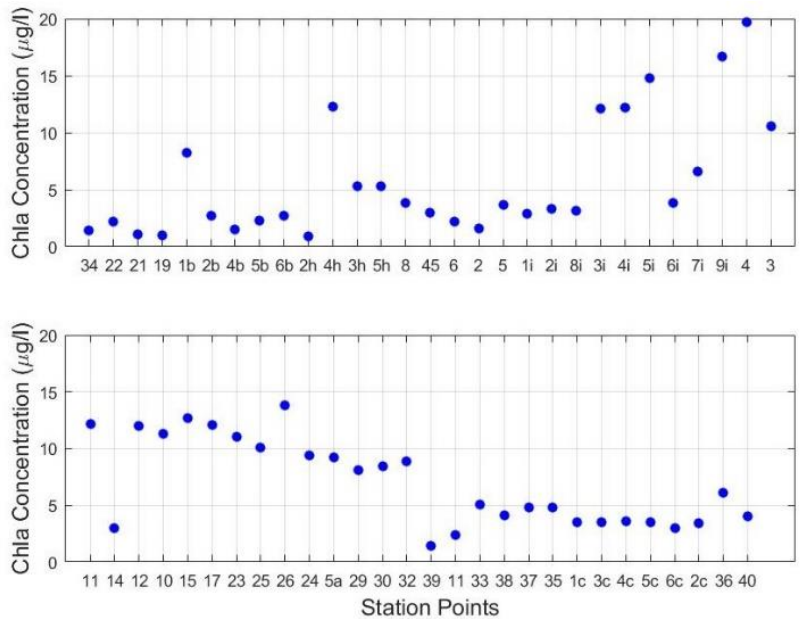

Figure 2. In situ chlorophyll-a data (July, 2018) were collected by MAREM (Artüz et al., 2018; Artüz et al., 2020).

2.2.2 Satellite Data: Landsat 8 satellite data and the combined data were used as satellite data. Landsat 8 satellite data are freely available in https://earthexplorer.usgs.gov/ website. The spectral bands of the Landsat 8 satellite image are coastal aerosol, blue, green, red, near infrared, SWIR 1, SWIR 2, cirrus, panchromatic, thermal infrared 1 and thermal infrared 2 . The temporal resolution of the satellite image is 16 days (Url-2). In this study, blue and green bands, which have $30 \mathrm{~m}$ spatial resolution (Url-2) were used.

Landsat 8 satellite data was used in order to detect chlorophyll-a concentration. While selecting satellite data, their synchronization with the acquisition date of the field data was considered. The Landsat images that used in this study were acquired on 25.07.2017 and 28.07.2018. In the study, one Landsat image frame was considered. 
After the coefficients of the model were found, the developed model was applied to the HLS data that was acquired on 23.02.2021. HLS data are freely available in https://search.earthdata.nasa.gov/search website. HLS data is the integration of the Sentinel-2 Multi-Spectral Imager and Landsat 8 Optical Land Imager. By means of the integration, it is possible to monitor land with two to three days temporal and $30 \mathrm{~m}$ spatial resolution. Two different types of the products, which are L30 and S30, were produced by the HLS project. In this study, S30 was used (Url-3).

One of the satellite data that used is SST daily data from 1981 to present derived from satellite observations Level-4 product, which is freely available in https://cds.climate.copernicus.eu/ website. This data is the integration of different sensors, which are SLSTR, ATSRs and AVHRRs. Level-4 product has global coverage. The horizontal resolution of the data is $0.05^{\circ}$ (Url-4). The combined data was used to determine the sea surface temperature data.

\subsection{Methodology}

In this research, water quality of the Sea of Marmara was assessed in 2017 and 2018. The flow chart that was followed for the methodology was shown in Figure 3.

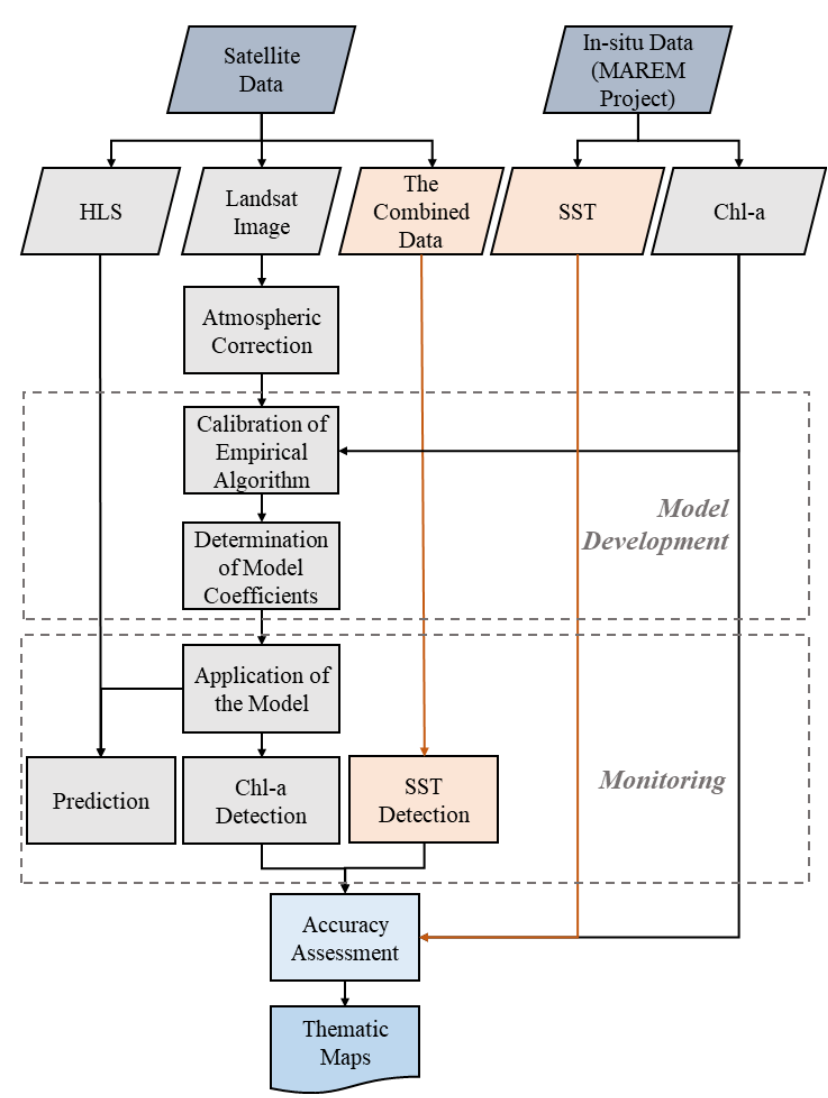

Figure 3. The flow chart of the methodology.

As a first step, the atmospheric correction process was applied to the Landsat 8 satellite images in order to retrieve surface reflectance values. ACOLITE processor was chosen to apply atmospheric correction (Vanhellemont and Ruddick, 2016; Vanhellemont and Ruddick, 2021). After the surface reflectance values were obtained, the OC2 model (O'Reilly et al., 1998), which was an empirical algorithm, was calibrated with 34 in-situ samples. Formula of OC2 model were given in Eq. (1)

$$
\begin{aligned}
& \mathrm{C}=10^{(\mathrm{a} 0+\mathrm{a} 1 \times \mathrm{R}+\mathrm{a} 2 \times \mathrm{R} 2+\mathrm{a} 3 \times \mathrm{R} 3)}+\mathrm{a} 4 \\
& \mathrm{R}=\log (\operatorname{Rrs} 490 / \operatorname{Rrs} 555)
\end{aligned}
$$

where $\quad \mathrm{a} 0, \mathrm{a} 1, \mathrm{a} 2, \mathrm{a} 3, \mathrm{a} 4=$ the coefficients of the model Rrs $490=$ Remote Sensing Reflectance at $490 \mathrm{~nm}$ Rrs $550=$ Remote Sensing Reflectance at $550 \mathrm{~nm}$

In the calibration process, $\mathrm{R}^{2}$ value was calculated as 0.5 . The calibration processes were shown in Figure 4 and the retrieved coefficients were given in the Table 2 .

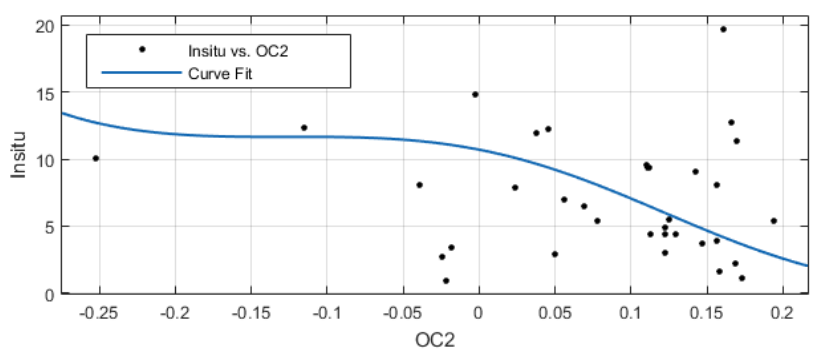

Figure 4. The correlation between the in-situ data and the model.

\begin{tabular}{|c|c|c|c|c|}
\hline $\mathrm{a} 0$ & $\mathrm{a} 1$ & $\mathrm{a} 2$ & $\mathrm{a} 3$ & $\mathrm{a} 4$ \\
\hline 1.029 & -0.9011 & -7.206 & -19.08 & 0 \\
\hline
\end{tabular}

Table 2. The retrieved coefficients.

After the calibration process, OC2 model was applied to Landsat 8 satellite data, the chlorophyll-a concentration distribution of the sea was generated. After the accuracy assessment process was applied, the model was applied to the HLS image to make predictions about chlorophyll-a concentration in 2021. In order to visualize the chlorophyll-a distribution of the sea, thematic maps were generated. On the other hand, the combined data were used in order to detect the SST distribution in this study. The correlation between the satellite data and ground truth data were examined.

\subsection{Accuracy Assessment}

Chlorophyll-a result of the OC2 model were compared with the 28 in-situ samples to assess the accuracy. On the other hand, the SST values that obtained from the combined data were verified by using in situ data. In this scope, bias and RMSE, which are the statistical metrics, were calculated by using the Eq.1 and Eq.2, respectively.

$$
\begin{aligned}
& \text { Bias }=\frac{1}{n} \sum_{i=1}^{n}\left(X_{o b s, i}-X_{\text {sensor }, i}\right) \\
& R M S E=\sqrt{\frac{\sum_{i=1}^{n}\left(X_{o b s, i}-X_{\text {sensor }, i}\right)^{2}}{n}}
\end{aligned}
$$

where $\quad X_{o b s}=$ the in-situ data

$X_{\text {sensor }}=$ the data acquired from the satellite data

The Bias and RMSE of the chlorophyll-a concentration estimation were calculated as $0.73 \mu \mathrm{g} / \mathrm{l}$ and $5.80 \mu \mathrm{g} / \mathrm{l}$, respectively.

On the other hand, the bias and RMSE of the combined data that obtained on 19.07.2017 were calculated as $0.33^{\circ} \mathrm{C}$ and $1.12{ }^{\circ} \mathrm{C}$, 
respectively by using 56 in-situ samples. The bias and RMSE of the combined data that obtained on 18.07.2018 were calculated as $-0.02^{\circ} \mathrm{C}$ and $1.03^{\circ} \mathrm{C}$, respectively by using 50 in-situ samples.

\section{RESULTS AND CONCLUSION}

After the coefficients were obtained, the model was applied to Landsat 8 images to retrieve chlorophyll-a concentrations (Figure $5 \mathrm{a}$ and $\mathrm{b})$. In figure $5 \mathrm{~b}$, cloud covered areas were masked and shown with black colour. The subset region was selected and shown with the black box in Figure 5b. The developed model was also applied to the HLS data for this subset region as shown in Figure 6.

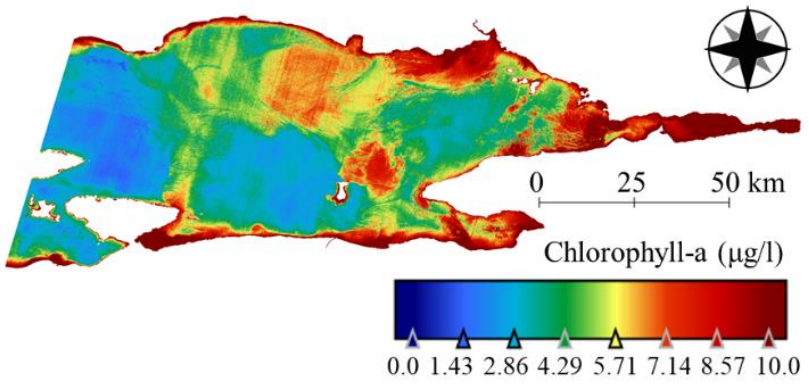

(a)

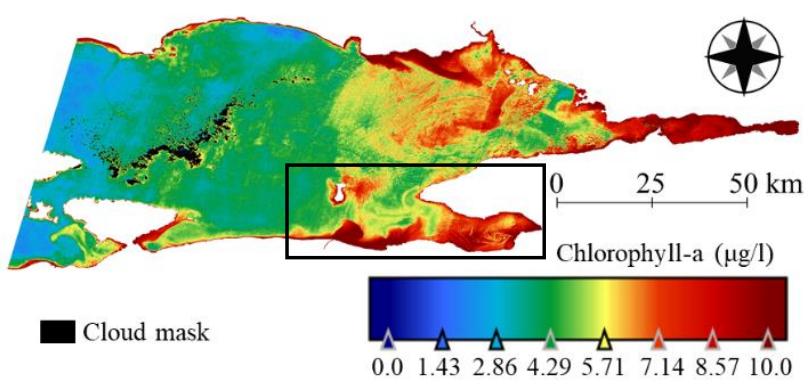

(b)

Figure 5. The distribution of chlorophyll-a concentration in a) 2017 b) 2018.

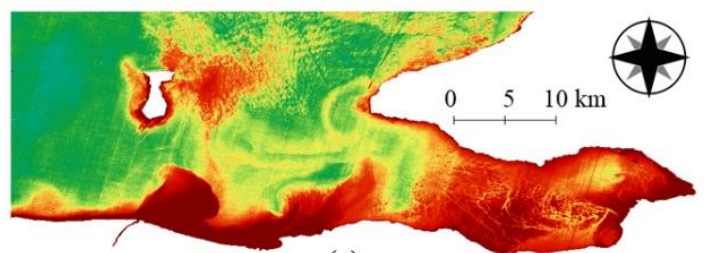

(a)

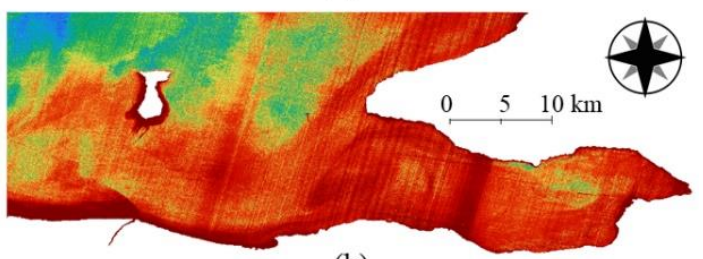

(b)

Chlorophyll-a $(\mu \mathrm{g} / \mathrm{l})$

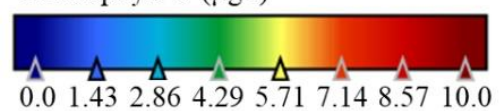

Figure 6. The distribution of chlorophyll-a concentration that retrieved by using a) Landsat 8 satellite data (2018), b) HLS data $(2021)$
When the thematic maps of the chlorophyll-a concentration distribution were examined, it was seen that the Sea of Marmara is a highly dynamical water body and chlorophyll-a concentration distribution was affected by the currents. Especially, strong current of the Bosphorus strait has a profound effect on the Sea of Marmara. High chlorophyll-a concentration was observed in İzmit and Gemlik Gulf. Region around the Sea of Marmara is heavily populated with urban areas such as Istanbul, Bursa and Kocaeli. These urban and industrial areas are important pollution sources around the Sea of Marmara (Url-5). As can be seen in the thematic maps that are generated in this study, Gulf of Izmit, which is the most industrialized part of the region, is the most polluted part of the Sea. Other most polluted areas are the plume region of the Bosphorus Strait, Gulf of Gemlik, which is another industrialized region, and Bandirma Gulf. There are not many changes in terms of the chlorophyll-a concentration between 2017 and 2018 summer seasons. When the Figure 6 was examined, it was seen that similar results were obtained with Landsat 8 and HLS data. Although, the accuracy of the HLS data could not be verified with the in-situ data, similar results were obtained with the in-situ measurements that were collected in previous years. Thus, it can be said that HLS data is a proper data to monitor chlorophyll-a concentration by interpreting the results visually.

After the sufficient results were obtained in the accuracy assessment of the SST values that obtained from the combined data, thematic maps were generated. Thematic maps of SST that belongs to the Sea of Marmara and its environment were presented in Figure 7 a, b.

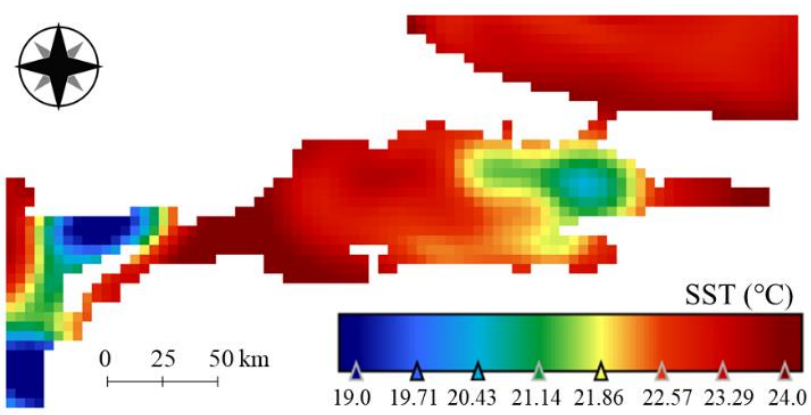

(a)

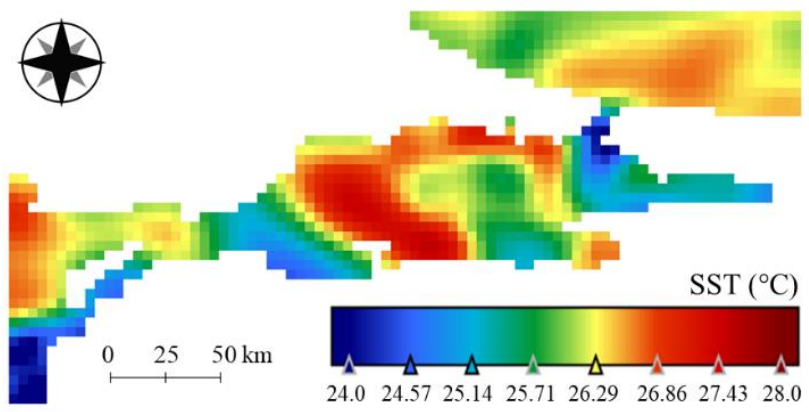

(b)

Figure 7. Thematic map of SST derived from the combined data that was acquired a) on 19.07.2017, b) 18.07.2018.

When the results of the combined data were examined, it was seen that the SST was increased by $3{ }^{\circ} \mathrm{C}$ from 2017 to 2018 . This situation was also verified by in situ data. Mean SST values of 
the samples were measured as 22.5 and 25.57 respectively, in 2017 and 2018.

Monitoring water quality by using remote sensing data and technologies has a profound impact on environment since it enables monitoring large areas. Although using satellite data has many advantages, in situ data is necessary to calibrate the model and verify results. The in-situ samples that correspond to cloud covered pixels were not used in the calibration and validation processes.

In addition, it was seen that the combined data is the proper data to monitor SST. One of the main advantages of the combined data and HLS data is having high temporal resolution. Like every optical data, HLS data that are obtained in cloudless weather conditions can be preferred to monitor the SST. The temporal resolution is important resolution type for monitoring water areas that are dynamic structures especially if there are large number of currents in the study area such as the Sea of Marmara.

\section{ACKNOWLEDGEMENTS}

The authors would like to acknowledge to MAREM (Marmara Environmental Monitoring) Project (Artüz et al., 2018; Artüz et al., 2020), which is a published and free data.

\section{REFERENCES}

Alparslan, E., Coskun, H. G., Alganci, U., 2009: Water quality determination of Küçükçekmece Lake, Turkey by using multispectral satellite data. The Scientific World Journal,9, 1215-1229.

Arias-Rodriguez, L. F., Duan, Z., Sepúlveda, R., MartinezMartinez, S. I., Disse, M., 2020: Monitoring water quality of Valle de Bravo reservoir, Mexico, using entire lifespan of MERIS data and machine learning approaches. Remote Sensing, 12(10), 1586.

Artüz M.L., Artüz O.B., Gülen D., Sakınç M., Yalçın B., Tunçer S., Yılmaz N., 2018: Marmara Denizi'nin Değişen Oşsinografik Şartlarının İlenmesi Projesi (MAREM) 2017 Senesi Çalışma Verileri. [Monitoring of the changing oceanographic conditions of the Sea of Marmara (MAREM), data of the year 2017.] Türkiye Barolar Birliği. Ankara, Turkey. [In Turkish.]

Artüz M.L., Artüz O.B., Gülen D., Sakınç M., Yalçın B., Tunçer S., 2020: Marmara Denizi'nin Değişen Oşinografik Şartlarının İzlenmesi Projesi (MAREM) 2019 Senesi Çallşma Verileri. [Monitoring of the changing oceanographic conditions of the Sea of Marmara (MAREM), data of the year 2018.] Türkiye Barolar Birliği. [In Turkish.]

Beşiktepe, Ş. T., Sur, H. İ., Özsoy, E., Latif, M. A., Oğuz, T., Ünlüata, Ü., 1994: The circulation and hydrography of the Marmara Sea. Progress in Oceanography, 34(4), 285-334.

Chawla, I., Karthikeyan, L., Mishra, A. K., 2020: A review of remote sensing applications for water security: Quantity, quality, and extremes. Journal of Hydrology, 585(6), 124826.

Constantin, S., Doxaran, D., Constantinescu, Ş., 2016: Estimation of water turbidity and analysis of its spatio-temporal variability in the Danube River plume (Black Sea) using MODIS satellite data. Continental Shelf Research, 112, 14-30.
Ekercin, S., 2007: Water quality retrievals from high resolution IKONOS multispectral imagery: A case study in Istanbul, Turkey. Water, Air, and Soil Pollution, 183(1), 239-251.

Fingas, M., 2019: Remote sensing for marine management. World seas: An environmental evaluation, Volume III: Ecological Issues and Environmental Impacts, 103-119. Academic Press.

Gholizadeh, M. H., Melesse, A. M., Reddi, L., 2016: A comprehensive review on water quality parameters estimation using remote sensing techniques. Sensors, 16(8), 1298.

Ikis, D. 2007: Temporal and Spatial Changes of Primary Productivity in the Sea of Marmara Obtained by Remote Sensing. MS Thesis, Middle East Technical University, Ankara, Turkey.

Kim, H. C., Son, S., Kim, Y. H., Khim, J. S., Nam, J., Chang, W. K., Lee, J. H., Lee, C. H., Ryu, J., 2017: Remote sensing and water quality indicators in the Korean West coast: Spatiotemporal structures of MODIS-derived chlorophyll-a and total suspended solids. Marine Pollution Bulletin, 121(1-2), 425-434.

O'Reilly, J. E., Maritorena, S., Mitchell, B. G., Siegel, D. A., Carder, K. L., Garver, S. A., Kahru M., McClain, C., 1998: Ocean color chlorophyll algorithms for SeaWiFS. Journal of Geophysical Research: Oceans, 103(C11), 24937-24953.

Ormeci, C., Sertel, E., Sarikaya, O., 2009: Determination of chlorophyll-a amount in Golden Horn, Istanbul, Turkey using IKONOS and in situ data. Environmental Monitoring and Assessment, 155(1-4), 83-90.

PAP/RAC, 2005: Coastal area management in Turkey, Priority Actions Programme Regional Activity Centre, Split.

Singh, S., Bhardwaj, A., Verma, V. K., 2020: Remote sensing and GIS based analysis of temporal land use/land cover and water quality changes in Harike wetland ecosystem, Punjab, India. Journal of Environmental Management, 262, 110355.

State Planning Organization (SPO), 2001: 8th Five-Year Development Plan, watersheds, watershed usage and Management Special Task Committee report, Ankara.

Sunar, F., 1992: Water-quality assessment in the Izmit Bay using Landsat-TM image data. The Photogrammetric Journal of Finland, 13(1), 79-86.

TÜDAV (Türk Deniz Araştırmaları Vakfi), 2017. 2017 Yılı Türkiye Denizleri raporu. Retrieved from <http://tudav.org/wpcontent/uploads/2018/04/TUDAV_2017_Denizler_Raporu_s.pd f >, retrieved date: 01.02.2021.

Tuzcu A., Dervişoğlu A., Musaoğlu N., Tanık A. G., 2019: Determination of land-use/cover and water turbidity of wetlands by using high resolution satellite image, International Symposium on Applied Geoinformatics (ISAG 2019), 1(1), 154158.

Url-1:< https://earthobservatory.nasa.gov/globalmaps/MY1DMM_CHLORA, retrieved date 21.04.2021

Url-2:< https://www.usgs.gov/core-sciencesystems/nli/landsat/landsat-8?qtscience_support_page_related_con $=0 \# q \mathrm{q}-$ science_support_page_related_con >, retrieved date 11.04.2021 
Url-3:<https://earthdata.nasa.gov/esds/harmonized-landsatsentinel-

2\#: :text=The\%20Harmonized\%20Landsat\%20Sentine1\%2D2, generate $\% 20 \mathrm{a} \% 20$ harmonized $\% 2 \mathrm{C} \% 20$ analysis $\% 2$ Dready $>$, retrieved date 21.04.2021

\section{Url-4}

https://cds.climate.copernicus.eu/cdsapp\#!/dataset/satellite-seasurface-temperature?tab=overview $>$, retrieved date 26.01.2021

Url-5:<

https://marmara.gov.tr/en/calisma_alanlarimiz/marmara-sea/, retrieved date 21.04.2021

Vanhellemont Q., Ruddick K., 2016: ACOLITE for Sentinel-2: Aquatic applications of MSI imagery. The 2016 ESA Living Planet Symposium, Prague, Czech Republic, 9-13 May 2016, ESA Special Publication SP-740.

Vanhellemont, Q., Ruddick, K., 2021: Atmospheric correction of Sentinel-3/OLCI data for mapping of suspended particulate matter and chlorophyll-a concentration in Belgian turbid coastal waters. Remote Sensing of Environment, 256, 112284. 